\title{
Coral size, health and structural complexity: effects on the ecology of a coral reef damselfish
}

\author{
Sam H. C. Noonan ${ }^{1,3, *}$, Geoffrey P. Jones ${ }^{1,2}$, Morgan S. Pratchett ${ }^{2}$ \\ ${ }^{1}$ School of Marine and Tropical Biology, and ${ }^{2}$ ARC Centre of Excellence for Coral Reef Studies, James Cook University, \\ Townsville, Queensland 4810, Australia \\ ${ }^{3}$ Australian Institute of Marine Science, Townsville, Queensland 4810, Australia
}

\begin{abstract}
The structure and dynamics of animal populations are strongly influenced by the physical and biotic characteristics of their habitats. However, in complex habitats such as coral reefs, the particular habitat features that are important and the mechanisms that impact on populations are poorly understood. This study investigates the influence of coral colony size, health and branching structure of the host coral Seriatopora hystrix on the ecology of the resident damselfish Chromis retrofasciata. Field observations indicated C. retrofasciata preferentially occupied larger $S$. hystrix colonies, but among occupied corals, group size was greatest on colonies of an intermediate size and with wider branch spacing. Healthy corals were observed to support higher abundances. The effects of both coral health (live vs. dead) and coral complexity (fine, medium and coarse branching) on survivorship of stocked juvenile C. retrofasciata were examined in a patch reef experiment. Survival was $20 \%$ higher in living colonies compared to dead ones, and fish in medium complexity coral exhibited approximately 10 and $20 \%$ greater survival than those in both the low and high complexity categories, respectively. These factors had an additive effect with the highest survival observed on healthy colonies with intermediate complexity (95\%) and the lowest on highly complex, dead corals $(55 \%)$. Body size distributions were also reduced on corals with the narrowest branch spacing. During habitat selection trials, juveniles were observed to preferentially occupy colonies with intermediate branch spacing. Prey may prefer corals of intermediate spacing and survive better as such habitats provide shelter that obstructs predator access. This study provides evidence that suggests small reef fish species will be sensitive to disturbances that result in the loss of live coral and alter preferred structural complexity of habitats.
\end{abstract}

KEY WORDS: Chromis retrofasciata $\cdot$ Coral reef $\cdot$ Reef fish $\cdot$ Habitat structure $\cdot$ Habitat complexity · Predation $\cdot$ Seriatopora $\cdot$ Survivorship

\section{INTRODUCTION}

It is widely acknowledged that habitat characteristics can be major drivers of the structure and dynamics of animal communities and their constituent populations (Bell \& Galzin 1984, Wiens 1989). The quality of a habitat for any species can depend on numerous characteristics such as patch size, structural complexity and habitat condition (Anderson 1978, Gorman \& Karr 1978, McIntyre 1995, Wilson et al. 2006, Thompson et al. 2007). These different habitat features can vary in their importance and differ in their influence on key ecological processes such as habitat selection and predation (Tolimieri 1995, Almany 2004b). Habitat characteristics appear to be particularly important in complex biotic habitats, such as rainforests (McIntyre 1995) and coral reefs (Friedlander \& Parrish 1998, Jones \& Syms 1998). However, given that there are numerous attributes of complex habitats that are potentially important, the key factors and the actual mechanisms by which they impact on populations are not always known, which limits our understanding of how populations will respond to habitat change. 
Variable patch size, coral health and physical structure have all been shown to influence population dynamics of coral-associated reef fishes (Tolimieri 1995, Holbrook et al. 2000, Holbrook \& Schmitt 2003, Aburto-Oropeza et al. 2007, Thompson et al. 2007, Schiemer et al. 2008, Bonin et al. 2012). To date a range of responses have been observed for different habitat attributes. For example, patch size appears to determine group size for some coraldwelling fishes (Schmitt \& Holbrook 1999, Thompson et al. 2007), while for others, fewer, larger individuals control larger patches (Munday et al. 1998, Kane et al. 2009). Susceptibility to predation, recruitment success and sub-lethal condition have all been linked to changes in coral health, even for species that have no direct dependence on live coral (Feary et al. 2007b, Coker et al. 2009, McCormick 2009, McCormick et al. 2010). The shelter habitat structure affords an inhabitant results from the relative sizes of predators and prey, and the space each has access to (Hacker \& Steneck 1990, Eggleston \& Lipcius 1992, Wahle 1992, Hixon \& Beets 1993). As such, the shelter provided by a given coral will differ both between fishes and between ontogenetic stages of single species (Dahlgren \& Eggleston 2000, Pratchett et al. 2008a, Schmitt et al. 2009).

There is a need to better understand the role habitat characteristics play in structuring reef fish populations, particularly as coral reefs are now under pressure from a suite of threats that impact on a range of habitat characteristics (Jones \& Syms 1998, Hughes et al. 2003, Bellwood et al. 2004, Munday et al. 2008, Pratchett et al. 2008b). Fish communities may respond to both changes in live coral cover and change in the physical structure of the habitat (Pratchett et al. 2008b), but the relative importance of these factors is not known. Distinguishing between the influence of live coral cover and structural complexity is not straightforward as these 2 components of habitat may be inextricably linked. That is, as the cover of complex coral increases, so does the overall complexity. Furthermore, corals that are most structurally complex are often those which are most susceptible to disturbances (De'ath \& Moran 1998, Graham et al. 2006, Pratchett et al. 2008b), and rapid erosion and structural loss of the exposed skeleton soon follows tissue loss (Marshall \& Baird 2000, Graham et al. 2006, Alvarez-Filip et al. 2009). For species of fish that occupy a structurally and biologically diverse range of habitat types, the influence of live coral cover is predicted to be minimal and habitat associations to be primarily governed by the need to shelter (Munday 2004, Wilson et al. 2008). However, the relative importance of these 2 critical components of habitat remains to be demonstrated.

To date, experimental studies that have examined the influence of coral habitat structure on associated fishes have compared structural differences between species of coral (see Jones 1988, Beukers \& Jones 1998, Nemeth 1998, Almany 2004a,b, Bonin et al. 2008). The use of different coral species makes it difficult to isolate the effects of differences in structure from other potential differences between coral species. Many coral species exhibit substantial intraspecific morphological variation (Veron \& Pichon 1976, Vytopil \& Willis 2001, Schiemer et al. 2008, Kane et al. 2009) that may have a dramatic influence on the quality of the shelter they provide to fishes.

This study combined observational and experimental approaches to examine the significance of coral colony size, coral partial mortality and coral branching structure on the ecology of an associated damselfish. It utilised the naturally occurring morphological variation of a single coral species to examine the effects of microhabitat structure on the distribution and demography of the black bar chromis Chromis retrofasciata. Field surveys were employed to test whether patterns of $C$. retrofasciata abundance related to characteristics of the needle coral Seriatopora hystrix habitat. Experimental studies were then undertaken to test whether these habitat factors influence habitat selection, body condition and survival. An experiment using patch reefs was undertaken to understand how coral structural and health variants influenced predation rates and physiological condition of stocked early postsettlement $C$. retrofasciata recruits. We predicted that both habitat factors would be influential, but that the effects of coral health would be less than that of branching structure. A second experiment examined habitat selection preferences, based on structural variation, by early post-settlement $C$. retrofasciata recruits. We predicted individuals would show a preference for the branch structure for which maximum survivorship was observed.

\section{MATERIALS AND METHODS}

\section{Study site and species}

The study was conducted during October and November 2009 in Kimbe Bay, West New Britain Provence, Papua New Guinea (5 $\left.30^{\prime} \mathrm{S}, 150^{\circ} 15^{\prime} \mathrm{E}\right)$. Surveys and patch reef experiments were performed on the fringing reefs on the western side of the bay, adjacent to the Mahonia Na Dari (MND) research 
and conservation centre (Fig. 1). The region has a history of habitat disturbance; destructive fishing techniques were once common practice: extensive land clearance of low-lying coastal areas has led to increased sedimentation levels from terrestrial runoff; and coral bleaching and crown of thorns starfish outbreaks have also been recorded in recent years (Jones et al. 2004, Munday 2004).

The needle coral Seriatopora hystrix (Dana, 1846) is an abundant scleractinian coral of the family Pocilloporidae (Veron 1986). S. hystrix displays marked morphological variation in its branching structure, in response to the microenvironment in which it grows (Veron \& Pichon 1976), ranging from those which are very compact, being composed of short branches that frequently bifurcate, to those which are more elongate and bifurcate infrequently (Veron \& Pichon 1976). The morphological variation within this species is much larger than differences between some congenerics (e.g. Acropora) and is expected to influence patterns of habitat use by coral-dwelling fishes (Kane et al. 2009, Messmer et al. 2011).

The black bar chromis Chromis retrofasciata (Weber, 1913) is an abundant planktivorous damselfish (Pomacentridae), commonly found throughout Kimbe Bay. Although C. retrofasciata tend to associate with a broad range of scleractinian and non-scleractinian corals, as well as branching sponges, most individuals (62\%) associate with Seriatopora hystrix. This is more than expected given $S$. hystrix abundance (Bonin 2012). Individuals are seen to forage
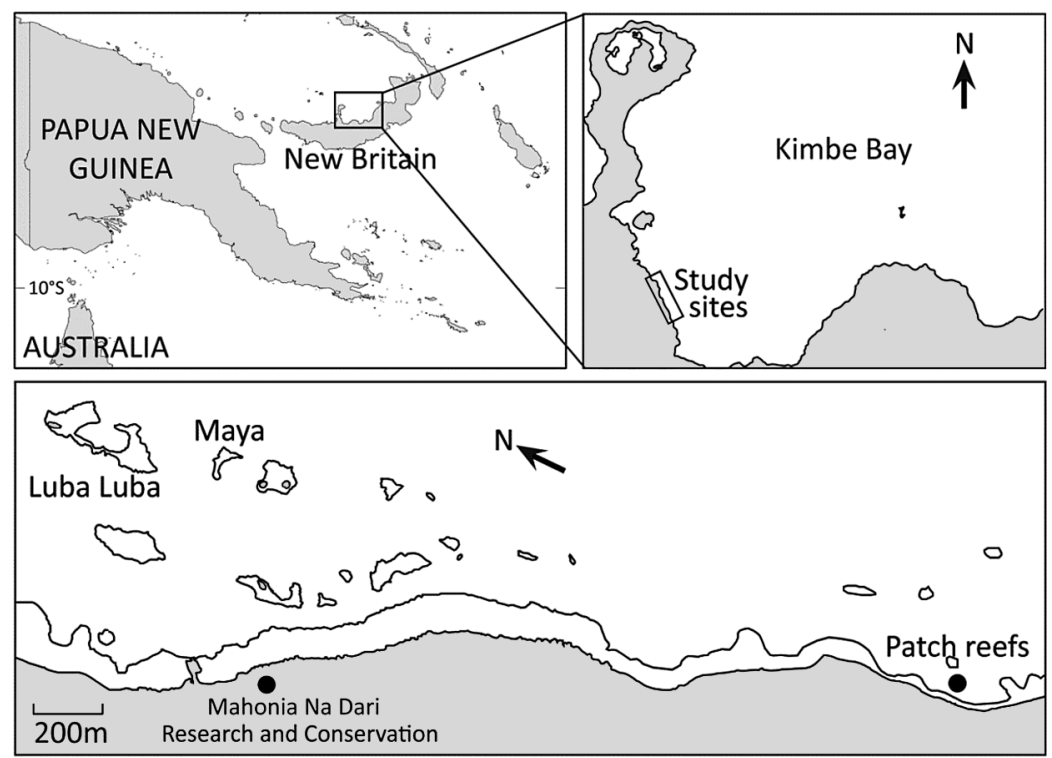

Fig. 1. Study site on the western side of Kimbe Bay, New Britain, Papua New Guinea. Location of the patch reef experiments and the 2 reefs surveyed are indicated above the colony during the day and retreat within the branching structure when threatened.

\section{Patterns of habitat use}

To assess patterns of habitat use in the wild, surveys were conducted on SCUBA at 2 reefs, Maya's and Luba Luba, in Kimbe Bay (Fig. 1). Surveys were conducted over a depth range of 1 to $25 \mathrm{~m}$ around the entire circumference of both reefs. Surveys commenced at a depth where a pair of divers following the contour of the reef encountered the deepest Seriatopora hystrix, and systematic sampling of all shallower colonies followed. Microhabitat characteristics of all $S$. hystrix colonies encountered, regardless of the presence or absence of Chromis retrofasciata individuals ( $\mathrm{n}=154$ colonies), as well as visual estimates of the size and number of any associating $C$. retrofasciata were recorded. The error in size estimations of C. retrofasciata individuals was examined before the surveys proper commenced. To do so, the observer visually estimated the size of all C. retrofasciata inhabiting a colony of $S$. hystrix before capturing them with a net and clove oil-ethanol mixture and measuring them in situ with callipers. Surveys commenced once error in size estimation was consistently $<10 \%$. Throughout the study a single observer estimated C. retrofasciata size to minimise bias.

The depth below the surface, size, extent of partial mortality and structural characteristics were recorded for every colony of Seriatopora hystrix encountered. Coral size was estimated as a hemisphere (Jokiel \& Morrissey 1986) using the mean of the maximum colony diameter, a perpendicular central diameter and height. This geometric estimation was used to quantify the size of colonies at its peripheries where fish larger than the branch spacing would be excluded. Coral mortality was visually estimated to the nearest $10 \%$. A quantitative index of habitat complexity was obtained by counting the number of branch tips that occurred within a $10 \times 10 \mathrm{~cm}$ quadrat placed over the centre of the colony, whereby the higher the number of branch tips per quadrat, the tighter the branch spacing. Colony height was recorded as the distance from the base of the colony to the top. For each coral colony, branch depth and spacing 
measurements were recorded with the wire end and nose of a pair of callipers, respectively, for 5 branch pairs. The 5 replicates of each branch metric were later averaged to give a single value for each per colony. Survey data were later used to compare characteristics of $S$. hystrix that contained resident Chromis retrofasciata to those which did not.

A multiple regression was carried out to determine the extent to which colony size, percent mortality, complexity, depth, height, branch spacing, branch depth, mean Chromis retrofasciata size and the number of other damselfishes as predictor variables explained variation in the group size of C. retrofasciata between colonies. Multiple regression models were optimised using a forward stepwise protocol and autocorrelations were considered visually with a correlation matrix. Those colonies supporting resident $C$. retrofasciata were classified as occupied, while those without were unoccupied. Data were pooled between reefs as there was no difference in the mean number of C. retrofasciata per colony of Seriatopora hystrix between the reefs (ANOVA: $F_{(1,152)}=2.37, \mathrm{p}>0.1$ ). ANOVA was used to compare colonies based on their occupancy or various characteristics of habitat. Where appropriate, Type I sum of squares was used in unbalanced ANOVA. All reported ANOVA results satisfied the assumptions of homoscedasticity, Gaussian distributions and independence.

\section{Effect of host structure and health on survivorship and condition}

An orthogonal patch reef experiment was conducted to test whether survivorship of juvenile Chromis retrofasciata varied with respect to 2 factors: (1) host coral health, and (2) structural complexity. The survivorship of stocked juvenile C. retrofasciata was monitored between Seriatopora hystrix patch reefs that differed in health (2 levels: alive and dead) and complexity (3 levels: low complexity = wide branch spacing; medium complexity; and high complexity = narrow branch spacing), including the fully crossed combinations of these factors. This factorial design equated to 6 separate treatments which were replicated 5 times each, resulting in 30 patch reefs. Patches consisted of a circular rubble base, with a diameter of approximately $80 \mathrm{~cm}$, upon which a single colony of $S$. hystrix was affixed.

The patch reef matrix was constructed approximately $10 \mathrm{~km}$ south of the MND research and conservation centre, on a large sandy section approximately $100 \mathrm{~m}$ offshore at a depth of 3 to $7 \mathrm{~m}$. A compass and tape measure were used to layout the patches, ensuring each patch was separated from other patches by at least $15 \mathrm{~m}$ and located no less than $20 \mathrm{~m}$ from other reef structure to minimise patch migration. Colonies were visually categorised into 1 of 3 complexity levels based on their branching structure, with the numbers of branch tips per quadrat of these groups then compared using the quadrat technique from the surveys and were deemed to be from statistically separate populations between complexity levels (ANOVA: $F_{(1,24)}=38.37, \mathrm{p}<0.001$, Tukey's honestly significant difference [HSD], all $\mathrm{p}<0.02$ ).

Having sorted colonies by structure, half within each category were then placed in fresh water for $10 \mathrm{~d}$ to remove all live tissue with water being replaced twice daily, after which colonies were then left in direct sunlight for $8 \mathrm{~h}$. These cleansing measures were imposed in an attempt to ensure dead corals were only providing structural shelter to associated fish, eliminating the contribution of live coral tissue or algal colonisation. The complexity of corals were considered homogeneous between the coral health levels (ANOVA: $F_{(1,24)}=0.78, \mathrm{p}>0.3$ ).

Previous studies have shown that branch space increases with colony size (Kuwamura et al. 1994, Schiemer et al. 2008, Kane et al. 2009). To account for this, colony size was kept constant for the different treatments (largest diameter range 21 to $28 \mathrm{~cm}$ ). Measurements indicated that colony size was not statistically different for either the complexity (ANOVA: $F_{(1,24)}=2.98, \mathrm{p}>0.05$ ) or health (ANOVA: $F_{(1,24)}=$ $3.07, \mathrm{p}>0.05)$ treatments. These colonies were then cleared of all resident fish with clove oil and placed into the experimental matrix using block randomisation. Mean patch depth was considered statistically the same for all complexity (ANOVA: $F_{(1,24)}=0.66, \mathrm{p}>$ 0.5 ) and health levels (ANOVA: $F_{(1,24)}=0.15, \mathrm{p}>0.5$ ).

Juvenile Chromis retrofasciata to be used in the experiment were collected from 3 reefs within $10 \mathrm{~km}$ of the patch reefs. All fish were tagged using a subcutaneous tag of fluorescent elastomer in the muscle block above the lateral line to uniquely identify all fish belonging to each patch. Fish were tagged $12 \mathrm{~h}$ prior to placement on the patch reefs to identify any immediate mortality due to this procedure. Before stocking, any other fish that were associating with the patches were removed. Each patch was then covered with a $1 \mathrm{~m}^{3}$ mesh cage with $0.2 \mathrm{~cm}$ mesh, and 8 juvenile fish were stocked per patch and allowed to settle into their new habitat. Patches were stocked over a $4 \mathrm{~d}$ period with patches remaining under the mesh cages for a minimum of $6 \mathrm{~h}$. This technique minimised any immediate emigration at stocking, which was 
limited to a single incident. In this case, another juvenile was stocked with an elastomer tag colour not used in the vicinity and was observed to survive for many days into the experiment (the emigrant was never relocated). The experiment was considered operational immediately after the cages were removed.

Daily counts of remaining Chromis retrofasciata were conducted on each patch to quantify persistence of tagged fish. Once settled, no movement of juvenile C. retrofasciata was observed between patches during the daily monitoring. As a result of this apparent lack of movement, any reduction in stocked numbers was attributed to in situ mortality. The small, vulnerable size of juveniles and their reliance on shelter habitat made it unlikely for them to traverse the great distance of open sand to other reef structures.

After $30 \mathrm{~d}$ of observations, any remaining juvenile Chromis retrofasciata were collected and euthanized with an overdose of clove oil to test for differences in physiological condition between habitat treatments, based on Fulton's condition factor, following Feary et al. (2009). Fulton's condition factor $(K)$ was defined as $K=W B \times 100 L^{-3}$; where $W B$ is the gutted body weight (g) and $L$ is the standard length (mm). High $K$ values indicate individuals are heavier for a given length, implying greater physiological condition. Fish weight was measured to the nearest $0.001 \mathrm{~g}$ using a HA-series digital balance. Two-way ANOVA was used to compare the Fulton's $K$ between the treatments.

Survival analysis was used to compare the survival curves from the patch reef experiment between the complexity and coral health treatments (KaplanMeier survival). The Kaplan-Meier method is a nonparametric estimator of survival that compares survival curves, rather than simply comparing the mean survivorship at the termination of the experiment (Coker et al. 2009). This technique also takes into consideration the survival time of individuals that died during the experiment (uncensored) and those that survived until the trial's end (censored).

\section{Effect of host structure on habitat preferences}

To determine whether structural characteristics of habitat would influence the habitat selection of earlystage post-settlement juvenile Chromis retrofasciata, the preferences of individual fish for colonies of increasing complexity were tested in the field. Three colonies of Seriatopora hystrix of equal size (24 to $27 \mathrm{~cm}$ maximum diameter) but varying complexity were laid out on a $3 \mathrm{~m}$ deep sandy patch in situ, at angles of $60^{\circ}$ and $50 \mathrm{~cm}$ apart. All 3 colonies were then enclosed within a large barrier net, with a $0.5 \mathrm{~cm}$ mesh size, to prevent experimental juveniles fleeing the area and/or the interference of other fish.

Each trial was conducted by placing one juvenile at a time in the centre of the colonies, under a transparent plastic container. This container was weighted down and attached to a surface line and float. The juvenile was allowed a 2 min period in which to settle after placement under the container, and to survey the potential habitats with which it was presented. After this time, an observer at the surface would slowly lift the plastic container, allowing the juvenile access to the colonies. The initial choice was compared to habitats used after a settlement period of at least $6 \mathrm{~h}$ (more often overnight) as initial selection may have simply been a flight response. The order of coral complexities was rotated after each trial to avoid any effect of colony location. Proportional differences in occupancy between the complexity levels after the settlement period were compared using a chi-squared homogeneity test.

\section{RESULTS}

\section{In situ distributions in relation to habitat characteristics}

A total of 154 Seriatopora hystrix colonies were surveyed, of which 78 were inhabited by Chromis retrofasciata $(50 \%)$. Group size ranged from 1 to 15 fish per colony with a median of 3 individuals for inhabited colonies (Fig. 2). The mean $( \pm \mathrm{SE})$ volume of

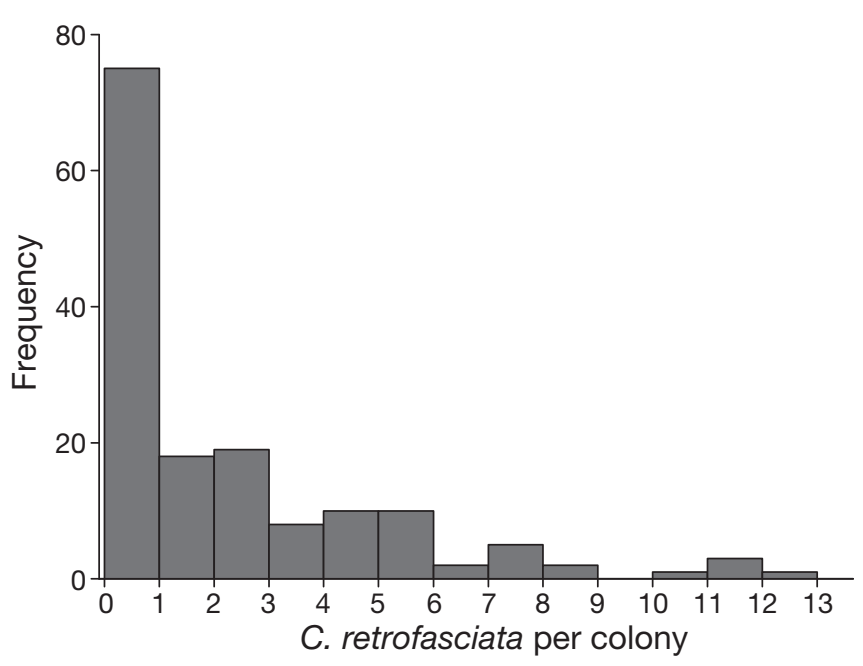

Fig. 2. Chromis retrofasciata occupying Seriatopora hystrix. Frequency histogram of the number of damselfish per coral colony. $\mathrm{N}=154$ 
occupied colonies $\left(1692.9 \pm 145.6 \mathrm{~cm}^{3}\right)$ was significantly larger than unoccupied colonies (1244.6 \pm $117.9 \mathrm{~cm}^{3}$ ) (ANOVA: $F_{(1,151)}=7.89, \mathrm{p}<0.01$ ). Occupied colonies also had significantly less branch tips per quadrat (indicative of wider branching or lower complexity) compared to unoccupied colonies (ANOVA: $\left.F_{(1,152)}=6.59, \mathrm{p}<0.02\right)$.

Variations in the group size of Chromis retrofasciata among occupied Seriatopora hystrix colonies were explained (ANOVA: $F_{(3,74)}=4.35, \mathrm{p}<0.001$ ) based on differences in colony size $(\beta=0.00054, \mathrm{p}=$ $0.029)$ and depth $(\beta=0.158, p<0.01)$. During model optimisation, colony height and colony size, as well as branch spacing and complexity were found to covary. The variable that explained the least variability, in each of these pairs of variables, was excluded during the stepwise model formulation as they did not explain significantly more variation when both were included in the model. The covariation observed between branch spacing and complexity confirms the validity of the quadrat technique, indicating that as the number of branch tips per quadrat decreased, the branch spacing increased. The explanatory variables in the final model were not seen to co-vary. Overall, this model could only account for $11.5 \%$ of the variation in the number of C. retrofasciata per colony of $S$. hystrix. The partial mortality and structural complexity of coral colonies had no apparent influence on C. retrofasciata group size $(\mathrm{p}>$ 0.05). However, the maximum number of C. retrofasciata per colony was greatest for colonies of an intermediate size (Fig. 3). The 'envelope' containing the observed values shows that both small and large colonies are unable to support high numbers of C. retrofasciata. Similarly, C. retrofasciata abundance was maximised on colonies with the lowest partial mortality (Fig. 4). None of the predictive variables measured were able to account for the observed C. retrofasciata size distributions.

Throughout the surveys, no correlations were detected between Seriatopora hystrix size, complexity or percent live tissue or between the abundance of Chromis retrofasciata and C. retrofasciata mean size (Table 1).

\section{Experimental evaluation of the effects of coral structure and health on fish survival and condition}

The experimental manipulation showed that survivorship was significantly higher on live corals, compared to dead corals (Cox's F-test: $F_{(34,80)}=$ $2.539, \mathrm{p}<0.001)$. Initial declines were observed on

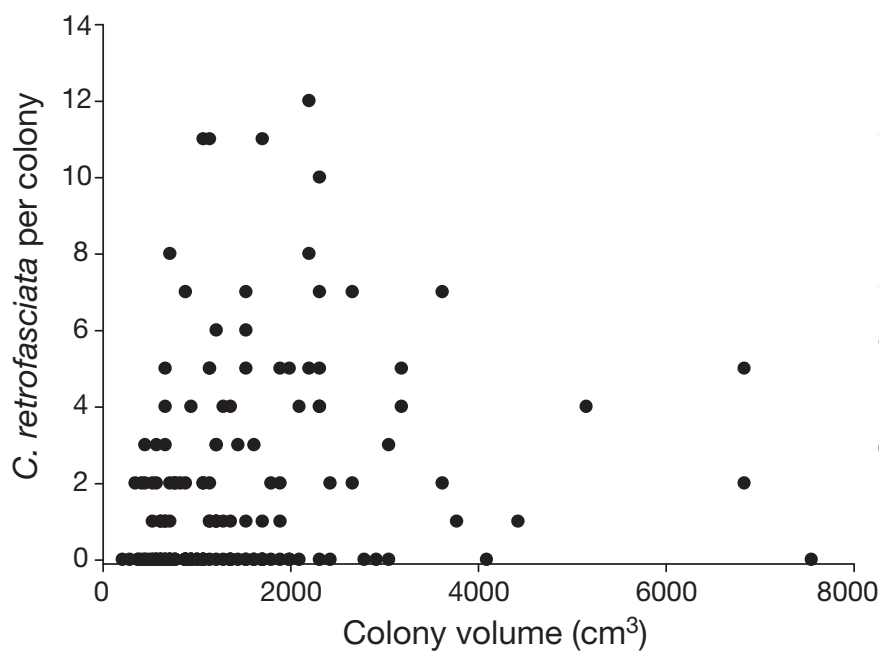

Fig. 3. Chromis retrofasciata occupying Seriatopora hystrix. Relationship between coral colony volume and the number of resident damselfish. $\mathrm{N}=154$
Table 1. Chromis retrofasciata occupying Seriatopora hystrix. Results of linear regression analyses between the different characteristics of $S$. hystrix colonies and between the number and mean size of inhabiting C. retrofasciata

\begin{tabular}{|lcccccc}
\hline Dependent variable & Independent variable & $\beta$ & $\mathrm{R}^{2}$ & \multicolumn{1}{c}{$t$} & $\mathrm{p}$ \\
\hline Colony complexity & Colony size & -0.081 & 0.006 & -1.000 & 0.319 \\
Percent live coral & Colony size & -0.147 & 0.022 & -1.826 & 0.070 \\
Colony complexity & Percent live coral & 0.005 & $<0.001$ & -0.057 & 0.954 \\
C. retrofasciata size & No. C. retrofasciata & 0.048 & 0.002 & 0.658 & 0.511 \\
& & & & & & \\
\hline
\end{tabular}

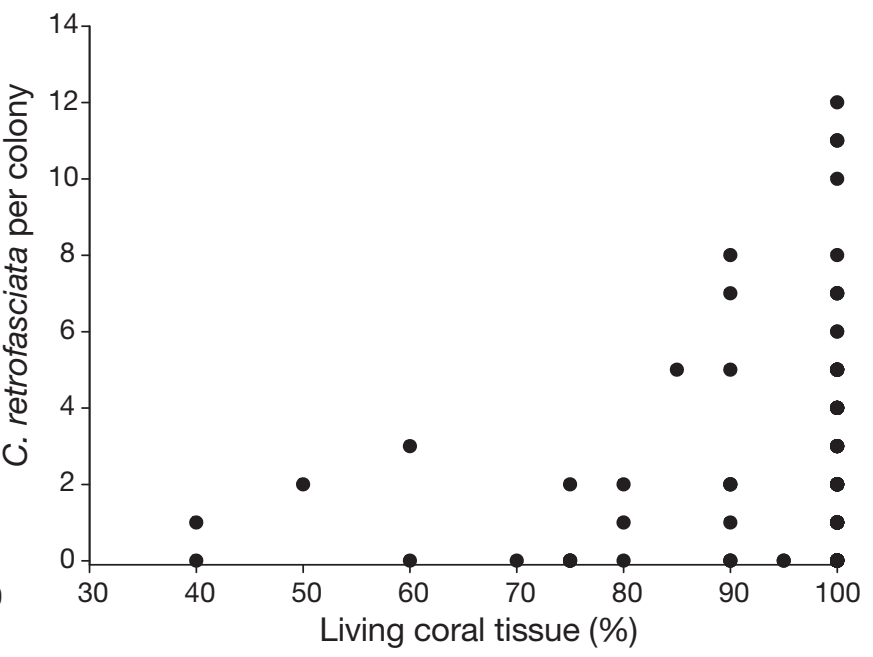

Fig. 4. Chromis retrofasciata occupying Seriatopora hystrix. Relationship between the percent living tissue per coral colony and the number of resident damselfish. $\mathrm{N}=154$ 
both live and dead colonies. However, the rate of decline remained higher on dead corals (Fig. 5a). At the end of the $30 \mathrm{~d}$ trial, 67 and $86 \%$ survival were observed on the dead and live treatments, respectively.

The structural complexity of coral habitat was also shown to influence survival (survival analysis: $\chi^{2}=$ 10.22, df $=2, \mathrm{p}<0.01$ ). While losses were observed for each of the complexity categories, the lowest survival was recorded with the high complexity corals (tightest branching structure), followed by the low then medium complexities due to differential rates of decline (Fig. 5b). Here, 65\% survival was recorded with the high complexity corals compared to 79 and $85 \%$ with the low and medium complexity categories, respectively.

No statistical interaction was observed between the 2 orthogonal treatments (coral health and com-

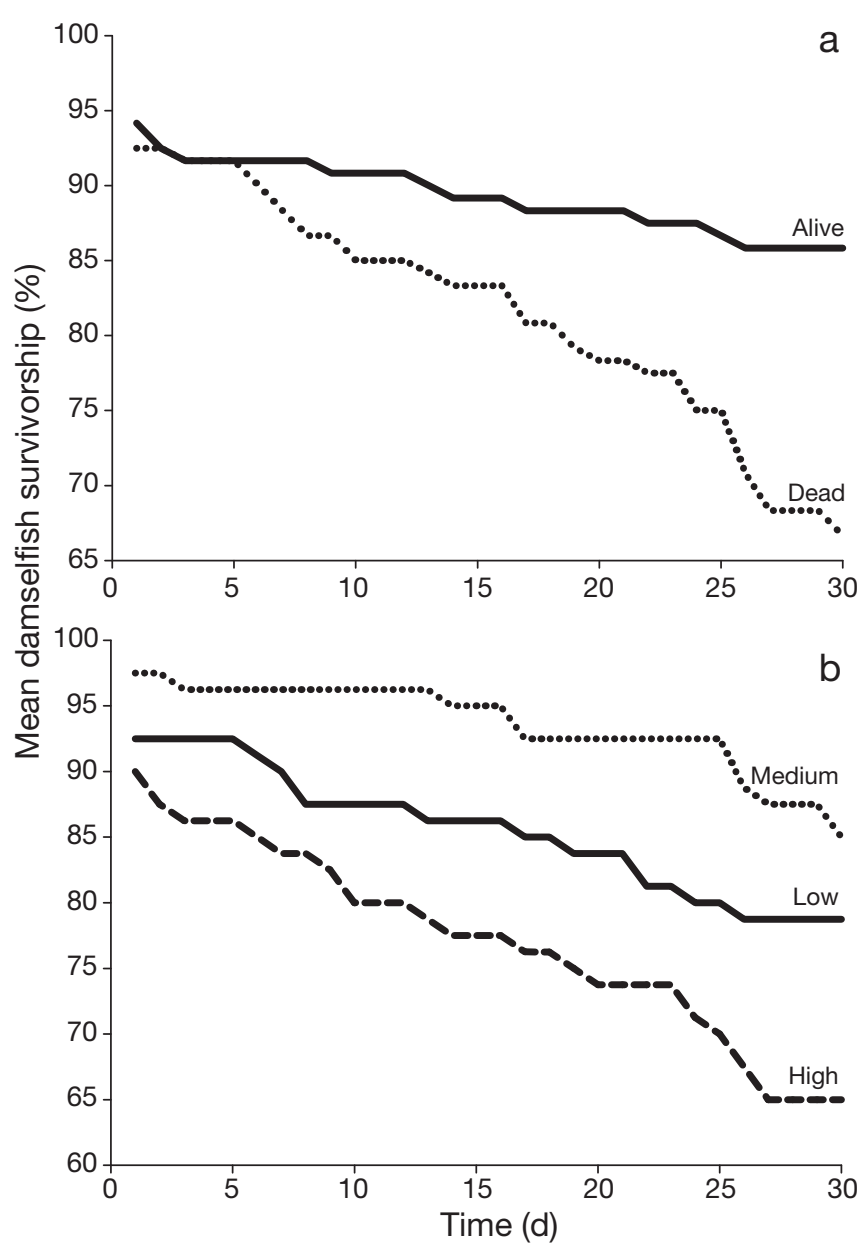

Fig. 5. Chromis retrofasciata occupying Seriatopora hystrix. Mean survivorship of the 8 stocked juvenile damselfish between (a) the live and dead treatments $(\mathrm{n}=15$ for each treatment) and (b) the 3 complexity treatments ( $\mathrm{n}=10$ for each treatment); high, medium and low. Mean total SE $=7.2 \%$ plexity), indicating that the magnitude of the effect of one factor is not dependent on the other. Overall, survivorship was highest on live corals with medium complexity (95\%) and lowest on dead corals with high complexity (55\%).

Numerous piscivorous fishes were observed within the study area, including trevallies (Carangidae), juvenile snappers (Lutjanidae), lizardfishes (Synodontidae) and flounders (Bothidae) that are known to prey upon juvenile damselfish (Holbrook \& Schmitt 2002). A predation event was also observed during a daily census, whereby a cryptic lizardfish captured a juvenile Chromis retrofasciata that strayed slightly from its patch.

The size distributions of remaining recruits differed between the patch complexity levels. On highly complex coral heads, where branch spacing was reduced, the mean $( \pm \mathrm{SE})$ standard length of remaining recruits was $17.32 \pm 0.2 \mathrm{~mm}$, compared to $18.93 \pm 0.4 \mathrm{~mm}$ and $18.30 \pm 0.2 \mathrm{~mm}$ for the medium and low complexities, respectively. As such, the remaining recruits on the highly complex coral heads were significantly smaller than the other 2 complexity categories, which were considered homogenous (ANOVA: $F_{(1,24)}=9.31, \mathrm{p}<0.002$, Tukey's HSD).

A comparison of the physiological condition of the surviving recruits at the end of the experiment indicated that there was little effect of the treatments on condition. There was also no significant difference in Fulton's $K$ between the health $\left(F_{(1,24)}=1.08, \mathrm{p}>0.3\right)$ and complexity $\left(F_{(1,24)}=1.99, \mathrm{p}>0.1\right)$ factors or their interaction $\left(F_{(2,24)}=3.105, \mathrm{p}>0.05\right)$.

\section{Effect of coral branching structure on habitat selection}

The 3 habitat complexity categories had a statistically significant effect on patterns of habitat selection by Chromis retrofasciata juveniles (chi-squared homogeneity: $\chi^{2}=6.62$, df $=2, p<0.05$ ). Initial selection tended to favour the low complexity category (Fig. 6). However, after the settlement period the medium and low complexity corals were utilised in even proportions. If the medium complexity colony was initially selected, no later movement was detected after the settlement period. Two of the 7 juveniles choosing low complexity corals moved into the medium complexity corals, while the single juvenile that initially chose a high complexity coral was later observed in the medium complexity coral. The highly complex category was never inhabited after the settlement period (Fig. 6). 


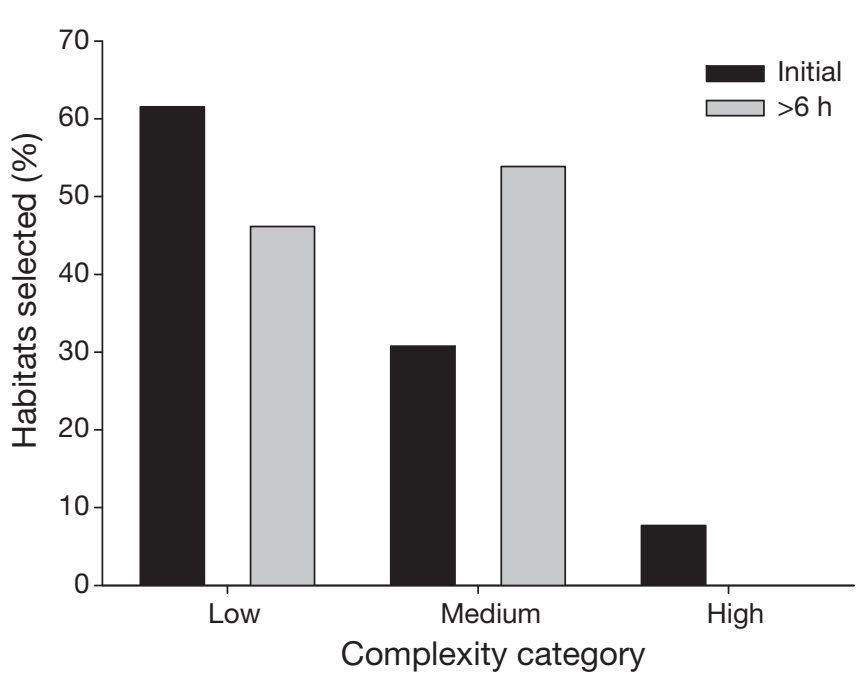

Fig. 6. Chromis retrofasciata occupying Seriatopora hystrix. Proportions of the habitats selected by C. retrofasciata recruits of differing complexity. Initial choice is compared to habitats utilised after a settlement period of at least $6 \mathrm{~h} . \mathrm{n}=13$

\section{DISCUSSION}

This study confirmed that a range of different habitat characteristics can influence the ecology and behaviour of a reef fish closely associated with the coral substratum. Variation in colony size, partial mortality and branch spacing of a single coral species (Seriatopora hystrix) all contributed in some way to explaining variation in group size, juvenile survival and habitat selection in the damselfish Chromis retrofasciata. Observational studies showed that group size was greatest on corals with an intermediate size and that occupied colonies were consistently larger and had wider branch spacing than unoccupied colonies. Coral partial mortality was also observed to influence group size, with $100 \%$ healthy corals supporting the largest groups. The experimental manipulation of coral health and branch spacing clearly showed that the survivorship of juvenile $C$. retrofasciata is influenced by the branch spacing and health of coral habitat. Here the lowest survival was observed in dead corals and those with the closest branch spacing and that the effects were additive when these factors were combined. The importance of branch spacing was also illustrated by the habitat choice experiment, which showed that juvenile $C$. retrofasciata actively avoid corals with the closest branch spacing.

The group size of Chromis retrofasciata was strongly influenced by the size of coral hosts, with the largest group size detected on intermediate-sized corals. Group size has been seen to correlate with patch size for a number of other coral-dwelling damselfishes (Sale 1972, Fricke 1980, Schmitt \& Holbrook 1999, Holbrook et al. 2000). The interior portion of a coral colony provides inhabitants with the most protection from predation (Holbrook \& Schmitt 2002), raising the carrying capacities of larger colonies (Jeffries \& Lawton 1984, Thompson et al. 2007). The observed decline in group size on larger colonies in the present study may be due to either sampling limitations (as there were few large colonies) or other ecological processes; larger patches may sustain potential predators or competitors that could reduce C. retrofasciata abundance (Belmaker et al. 2009, Schmitt et al. 2009). Other potentially limiting factors (larval supply, colony depth etc.) may have obscured the observed relationship between patch size and $C$. retrofasciata abundance; however, results suggest that smaller colonies are less preferable as they were uninhabited more frequently.

There is increasing evidence that suggests the health of coral habitat may be important for the survivorship and health of coral-dwelling fishes (Jones et al. 2004, Wilson et al. 2008, Coker et al. 2009, Feary et al. 2009, McCormick 2009, McCormick et al. 2010, Bonin et al. 2012). In the present study, both observational and experimental components indicated the maximum number of Chromis retrofasciata per colony was influenced by the amount of living coral tissue. Colonies with higher partial mortality were unable to support the larger groups seen in healthy colonies. The small group sizes seen in corals with higher partial mortality may be primarily due to differential predation. Partial colony mortality has been shown to have little influence on the settlement decisions of closely related damselfishes, and damselfish are unlikely to relocate to alternate habitats once settled (Feary et al. 2007a). Recent behavioural studies of damselfish occupying corals of degraded health have shown that these colonies attract increased mortality rates. Dominant individuals can force subordinate conspecifics out of degraded colonies (McCormick 2009), and prey species may be more conspicuous against a backdrop of degraded coral (Coker et al. 2009), both of which increase susceptibility to predation. It may be that, in the search for shelter, settling fish will not discriminate between habitats based on partial mortality (Feary 2007, Feary et al. 2007a); however, these corals ultimately have lower total carrying capacities. This response may simply be due to a detectable degradation in habitat quality as its integrity is beginning to fail (i.e. via later erosion of structure). If this was the case, it could be predicted that a similar response would be 
observed for C. retrofasciata inhabiting other forms of degraded habitat including branching sponges and is something that requires further investigation.

Variations in the branching structure of Seriatopora hystrix colonies were shown to influence the distributions of resident Chromis retrofasciata. Observations indicated that occupied colonies had wider branch spacing than those without resident $C$. retrofasciata. Shelter sizes in colonies with narrow branch spacing may have been too small to allow easy access for $C$. retrofasciata and subsequently provided little effective shelter (Hixon \& Beets 1993). Holbrook \& Schmitt (2002) showed that juvenile damselfish were 5 times more likely to be eaten by small predators that were closer to their own body size than larger ones, and subsequently chose shelter sites that exclude access to slightly larger predators (Shulman 1984, Hixon \& Beets 1993, Caley \& St. John 1996). In the survival experiment of this study, colonies with intermediate branch spacing could house the highest number of individuals. These colonies may accommodate an overlap of fish that are either too large to occupy small shelter sites or small individuals that receive little shelter from refuges much larger than their own body size (Hixon \& Beets 1993, Almany 2004a).

The observed differences in total length of Chromis retrofasciata between colonies with different branch spacing further supports the idea that shelter size may influence the body size of associates. The mean body length of remaining recruits from the survival experiment was seen to be lowest in colonies with narrower branch spacing. This may have been due to either size selective mortality or differential growth between colonies. There is some indication that coral branch space may influence growth rates of coraldwelling fishes, where smaller maximum size is attained in corals with tighter branch spacing (Munday 2001). Moreover, larger individuals may not be able to shelter within the small sites offered by the highly complex corals (Kane et al. 2009). Observed ontogenetic habitat shifts in reef fishes between separate coral species with different structures are frequently attributed to this need for differentially sized shelter as fish grow (Holbrook et al. 2000, Wilson et al. 2008, Belmaker et al. 2009). Unfortunately it is not possible to assign causation in this case, as length measurements were not attained prior to the commencement of the experiment.

Increased habitat complexity is often predicted to be beneficial for reef fishes as it can reduce encounter rates between predators and prey and modify predators' search and capture capabilities (Jones
1988, Beukers \& Jones 1998, Almany 2004b). However, numerous lines of evidence in the present study indicated colonies of Seriatopora hystrix with the narrowest branch spacing (high complexity) were not preferable habitat for Chromis retrofasciata. Juvenile C. retrofasciata were seen to actively avoid highly complex colonies, preferring those with larger shelter sites. Reef fish have long been known to actively select settlement sites (Sale et al. 1984, Victor 1986, Danilowicz 1996, Lecchini et al. 2007), and this choice may have fitness consequences that are realised at an early stage. Juveniles are most vulnerable shortly after settlement and high initial mortality is common (Holbrook \& Schmitt 2002, Almany \& Webster 2006). Even if juveniles successfully recruit to colonies with narrow branch spaces, larger shelter sites will be required as they grow. Any habitat shifts come with increased exposure to predation, and it may be that larger shelter sites are sought in order to maximise body size attainment before relocation is required (Munday \& Jones 1998).

This study has shown that the structure and health of coral habitat can influence the population dynamics and demographics of a coral-dwelling fish. Effects were seen for these 2 habitat characteristics in isolation and in combination with one another. Experimental survival was shown to be highest in live corals with medium branch spacing and lowest in dead colonies with the tightest branch spacing. Similarly, the survey data indicated that closer branch spacing and increasing partial mortality resulted in smaller maximum group sizes. This provides further evidence for the growing recognition that the health of coral habitat influences the wider reef fish community (Jones et al. 2004, Feary 2007, Munday et al. 2008, Wilson et al. 2008, Coker et al. 2009) and that sustained declines in both coral cover and coral health will have important ramifications for coral-dependent organisms such as Chromis retrofasciata. Furthermore, the fact that weaker effects were seen in colonies with wider branch spacing indicates that the complexity of Seriatopora hystrix may rarely be low enough under natural conditions to reduce the shelter offered to this species (hence the preferential association). The documented erosion of habitat complexity following live coral tissue loss, however, may reduce complexity enough to limit the shelter colonies of $S$. hystrix can provide. These findings indicate that fish species will be influenced by disturbances that affect not only the amount of live coral of preferred species, but also the patch size and structural characteristics.

Overall, this study indicates that potential carrying capacities or the availability of suitable habitat may 
not always depend on the abundance of a coral species. Heterogeneity in habitat quality needs to be considered in conjunction with habitat quantity in order to better understand ecological processes and species distributions. Future studies need to investigate what actually constitutes habitat quality, for individual species or species groups, by controlling for the effects of different habitat characteristics. These studies would allow for more accurate predictions of how habitat-dependent animals may respond to habitat disturbances.

Acknowledgements. We thank the Kilu and Tamare villages for allowing us access to their reefs and the staff of the Mahonia Na Dari Research and Conservation Centre and Walindi Plantation Resort for logistic support. Many thanks to A. Young, M. Giru and M. Takahashi for assistance in the field and M. Srinivasan for Fig. 1 preparation. This study was financially supported by grants to G.P.J. and M.S.P. within the Australian Research Council's Centre of Excellence for Coral Reef Studies.

\section{LITERATURE CITED}

Aburto-Oropeza O, Sala E, Paredes G, Mendoza A, Ballesteros E (2007) Predictability of reef fish recruitment in a highly variable nursery habitat. Ecology 88:2220-2228

> Almany GR (2004a) Differential effects of habitat complexity, predators and competitors on abundance of juvenile and adult coral reef fishes. Oecologia 141:105-113

Almany GR (2004b) Does increased habitat complexity reduce predation and competition in coral reef fish assemblages? Oikos 106:275-284

> Almany G, Webster M (2006) The predation gauntlet: early post-settlement mortality in reef fishes. Coral Reefs 25: $19-22$

Alvarez-Filip L, Dulvy NK, Gill JA, Cote IM, Watkinson AR (2009) Flattening of Caribbean coral reefs: region-wide declines in architectural complexity. Proc R Soc Lond B Biol Sci 276:3019-3025

Anderson JM (1978) A method to quantify soil-microhabitat complexity and its application to a study of soil animal species diversity. Soil Biol Biochem 10:77-78

Bell JD, Galzin R (1984) Influence of live coral cover on coral-reef fish communities. Mar Ecol Prog Ser 15: 265-274

Bellwood DR, Hughes TP, Folke C, Nystrom M (2004) Confronting the coral reef crisis. Nature 429:827-833

Belmaker J, Ziv Y, Shashar N (2009) Habitat patchiness and predation modify the distribution of a coral-dwelling damselfish. Mar Biol 156:447-454

Beukers JS, Jones GP (1998) Habitat complexity modifies the impact of piscivores on a coral reef fish population. Oecologia 114:50-59

Bonin MC (2012) Specializing on vulnerable habitat: Acropora selectivity among damselfish recruits and the risk of bleaching-induced habitat loss. Coral Reefs 31:287-297

> Bonin MC, Srinivasan M, Almany GR, Jones GP (2008) Interactive effects of interspecific competition and microhabitat on early post-settlement survival in a coral reef fish. Coral Reefs 28:265-274

Bonin MC, Almany GR, Jones GP (2011) Contrasting effects of habitat loss and fragmentation on coral-associated reef fishes. Ecology 92:1503-1512

Caley MJ, St. John J (1996) Refuge availability structures assemblages of tropical reef fishes. J Anim Ecol 65: 414-428

Coker DJ, Pratchett MS, Munday PL (2009) Coral bleaching and habitat degradation increase susceptibility to predation for coral-dwelling fishes. Behav Ecol 20:1204-1210

> Dahlgren CP, Eggleston DB (2000) Ecological processes underlying ontogenetic habitat shifts in a coral reef fish. Ecology 81:2227-2240

> Danilowicz BS (1996) Choice of coral species by naive and field-caught damselfish. Copeia 1996:735-739

> De'ath G, Moran PJ (1998) Factors affecting the behaviour of crown-of-thorns starfish (Acanthaster planci L.) on the Great Barrier Reef. 2. Feeding preferences. J Exp Mar Biol Ecol 220:107-126

> Eggleston DB, Lipcius RN (1992) Shelter selection by spiny lobster under variable predation risk, social conditions, and shelter size. Ecology 73:992-1011

Feary D (2007) The influence of resource specialization on the response of reef fish to coral disturbance. Mar Biol 153:153-161

> Feary DA, Almany GR, McCormick MI, Jones GP (2007a) Habitat choice, recruitment and the response of coral reef fishes to coral degradation. Oecologia 153:727-737

> Feary DA, Almany GR, Jones GP, McCormick MI (2007b) Coral degradation and the structure of tropical reef fish communities. Mar Ecol Prog Ser 333:243-248

> Feary DA, McCormick MI, Jones GP (2009) Growth of reef fishes in response to live coral cover. J Exp Mar Biol Ecol 373:45-49

- Fricke HW (1980) Control of different mating systems in a coral reef fish by one environmental factor. Anim Behav 28:561-569

- Friedlander AM, Parrish JD (1998) Habitat characteristics affecting fish assemblages on a Hawaiian coral reef. J Exp Mar Biol Ecol 224:1-30

Gorman OT, Karr JR (1978) Habitat structure and stream fish communities. Ecology 59:507-515

Graham NAJ, Wilson SK, Jennings S, Polunin NVC, Bijoux JP, Robinson J (2006) Dynamic fragility of oceanic coral reef ecosystems. Proc Natl Acad Sci USA 103:8425-8429

Hacker SD, Steneck RS (1990) Habitat architecture and the abundance and body-size-dependent habitat selection of a phytal amphipod. Ecology 71:2269-2285

Hixon MA, Beets JP (1993) Predation, prey refuges, and the structure of coral-reef fish assemblages. Ecol Monogr 63: 77-101

Holbrook SJ, Schmitt RJ (2002) Competition for shelter space causes density-dependent predation mortality in damselfishes. Ecology 83:2855-2868

> Holbrook SJ, Schmitt RJ (2003) Spatial and temporal variation in mortality of newly settled damselfish: patterns, causes and co-variation with settlement. Oecologia 135: $532-541$

> Holbrook SJ, Forrester GE, Schmitt RJ (2000) Spatial patterns in abundance of a damselfish reflect availability of suitable habitat. Oecologia 122:109-120

> Hughes TP, Baird AH, Bellwood DR, Card M and others (2003) Climate change, human impacts, and the resilience of coral reefs. Science 301:929-933

Jeffries MJ, Lawton JH (1984) Enemy free space and the structure of ecological communities. Biol J Linn Soc 23: 269-286 
Jokiel PL, Morrissey JI (1986) Influence of size on primary production in the reef coral Pocillopora damicornis and the macroalga Acanthophora spicifera. Mar Biol 91: $15-26$

> Jones GP (1988) Experimental evaluation of the effects of habitat structure and competitive interactions on the juveniles of two coral reef fishes. J Exp Mar Biol Ecol 123: 115-126

> Jones GP, Syms C (1998) Disturbance, habitat structure and the ecology of fishes on coral reefs. Austral Ecol 23: 287-297

> Jones GP, McCormick MI, Srinivasan M, Eagle JV (2004) Coral decline threatens fish biodiversity in marine reserves. Proc Natl Acad Sci USA 101:8251-8253

Kane CN, Brooks AJ, Holbrook SJ, Schmitt RJ (2009) The role of microhabitat preference and social organization in determining the spatial distribution of a coral reef fish. Environ Biol Fishes 84:1-10

Kuwamura T, Yogo Y, Nakashima Y (1994) Population dynamics of goby Paragobiodon echinocephalus and host coral Stylophora pistillata. Mar Ecol Prog Ser 103: 17-23

> Lecchini D, Planes S, Galzin R (2007) The influence of habitat characteristics and conspecifics on attraction and survival of coral reef fish juveniles. J Exp Mar Biol Ecol 341: 85-90

Marshall PA, Baird AH (2000) Bleaching of corals on the Great Barrier Reef: differential susceptibilities among taxa. Coral Reefs 19:155-163

McCormick MI (2009) Behaviourally mediated phenotypic selection in a disturbed coral reef environment. PLoS ONE 4:e7096

McCormick MI, Moore JAY, Munday PI (2010) Influence of habitat degradation on fish replenishment. Coral Reefs 29:537-546

McIntyre NE (1995) Effects of forest patch size on avian diversity. Landscape Ecol 10:85-99

> Messmer V, Jones GP, Munday PL, Holbrook SJ, Schmitt RJ, Brooks AJ (2011) Habitat biodiversity as a determinant of fish community structure on coral reefs. Ecology 92: 2285-2298

Munday PL (2001) Fitness consequences of habitat use and competition among coral-dwelling fishes. Oecologia 128: 585-593

Munday PL (2004) Habitat loss, resource specialization, and extinction on coral reefs. Glob Change Biol 10:1642-1647

Munday PL, Jones GP (1998) The ecological implications of small body size among coral-reef fishes. Oceanogr Mar Biol Annu Rev 36:373-411

Munday PL, Caley MJ, Jones GP (1998) Bi-directional sex change in a coral-dwelling goby. Behav Ecol Sociobiol 43:371-377

Munday PL, Jones GP, Pratchett MS, Williams AJ (2008) Climate change and the future for coral reef fishes. Fish Fish 9:261-285

> Nemeth RS (1998) The effect of natural variation in substrate architecture on the survival of juvenile bicolor damselfish. Environ Biol Fishes 53:129-141

Pratchett M, Berumen M, Marnane M, Eagle J, Pratchett D

Editorial responsibility: John Choat,

Townsville, Queensland, Australia (2008a) Habitat associations of juvenile versus adult butterflyfishes. Coral Reefs 27:541-551

> Pratchett MS, Munday PL, Wilson SK, Graham NAJ and others (2008b) Effects of climate-induced coral bleaching on coral-reef fishes-ecological and economic consequences. Oceanogr Mar Biol Annu Rev 46:251-296

Sale PF (1972) Influence of corals in the dispersion of the pomacentrid fish, Dascyllus Aruanus. Ecology 53: 741-744

> Sale PF, Douglas WA, Doherty PJ (1984) Choice of microhabitats by coral reef fishes at settlement. Coral Reefs 3 : 91-99

Schiemer L, Niedermuller S, Herler J (2008) The influence of colony size and coral health on the occupation of coralassociated gobies (Pisces: Gobiidae). Coral Reefs 28: $137-142$

> Schmitt RJ, Holbrook SJ (1999) Settlement and recruitment of three damselfish species: larval delivery and competition for shelter space. Oecologia 118:76-86

Schmitt RJ, Holbrook SJ, Brooks AJ, Lape JCP (2009) Intraguild predation in a structured habitat: distinguishing multiple-predator effects from competitor effects. Ecology 90:2434-2443

Shulman MJ (1984) Resource limitation and recruitment patterns in a coral reef fish assemblage. J Exp Mar Biol Ecol 74:85-109

Thompson V, Munday P, Jones G (2007) Habitat patch size and mating system as determinants of social group size in coral-dwelling fishes. Coral Reefs 26:165-174

Tolimieri N (1995) Effects of microhabitat characteristics on the settlement and recruitment of a coral reef fish at two spatial scales. Oecologia 102:52-63

Veron JEN (1986) Corals of Australia and the Indo-Pacific. Australian Institute of Marine Science Angus and Robertson, North Ryde

Veron JEN, Pichon M (1976) Scleractinia of Eastern Australia. Australian Institute of Marine Science Monograph Series, Vol 1, Part 1. Australian Government Publishing Service, Canberra

> Victor BC (1986) Larval settlement and juvenile mortality in a recruitment-limited coral reef fish population. Ecol Monogr 56:145-160

> Vytopil E, Willis B (2001) Epifaunal community structure in Acropora spp. (Scleractinia) on the Great Barrier Reef: implications of coral morphology and habitat complexity. Coral Reefs 20:281-288

Wahle RA (1992) Substratum constraints on body size and the behavioral scope of shelter use in the American lobster. J Exp Mar Biol Ecol 159:59-75

Wiens JA (1989) Spatial scaling in ecology. Funct Ecol 3: 385-397

- Wilson SK, Graham NAJ, Pratchett MS, Jones GP, Polunin NVC (2006) Multiple disturbances and the global degradation of coral reefs: are reef fishes at risk or resilient? Glob Change Biol 12:2220-2234

Wilson SK, Burgess SC, Cheal AJ, Emslie M and others (2008) Habitat utilization by coral reef fish: implications for specialists vs. generalists in a changing environment. J Anim Ecol 77:220-228

Submitted: August 25, 2011; Accepted: February 27, 2012 Proofs received from author(s): May 21, 2012 